\title{
Probiotics Effect on Psychiatric Illnesses and Autism
}

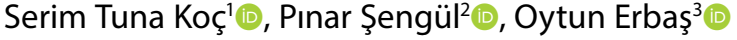

In 2020, the World Health Organization reported that mental disorders (e.g. schizophrenia, bipolar disorder, depression, dementia and eating disorders) affect 1 in 4 people. Depression is the most common disorder, affecting $4.4 \%$ of the global population. ${ }^{[1,2]}$

There is a mutual relationship between gut microbiota and the brain, instantiated in reciprocal connectivity via the autonomic nervous system. ${ }^{[3]}$ Moreover,studies have shown that dysbiosis of the intestinal microbiota can trigger neuropsychiatric problems such as schizophrenia, bipolar disorders and depression. ${ }^{[4]}$

The studies reviewed here indicate that diet may be associated with cognitive disorders. A Western-type diet, which is high in fats and sugars, increases the risk of anxiety and depression, while a Mediterranean-type diet is associated with reduced rates of depression. ${ }^{[5,6]}$

It is known that a diet rich in tryptophan reduces stress-related mood disorders by regulating serotonin levels. ${ }^{[7,8]}$ In addition, omega-3 polyunsaturated fatty acids and a diet rich in flavonoids has been shown to reduce the risk of depression. ${ }^{[7,9]}$

'Department of Nutrition and Dietetics, Yeditepe University Faculty of Medicine, Istanbul, Turkey

${ }^{2}$ Psychologist, Istanbul

${ }^{3}$ ERBAS Institute of Experimental Medicine, Illinois, USA \& Gebze, Turkey

Correspondence: Serim Tuna Koç. Yeditepe Üniversitesi Tıp Fakültesi, Beslenme ve Diyetetik Bölümü, 34755 Ataşehir, İstanbul, Türkiye

E-mail: stunakoc@hotmail.com

Cite this article as: Tuna Koç $S$, Şengül $P$, Erbaş $O$. Probiotics Effect on Psychiatric Illnesses and Autism. JEB Med Sci 2020;1(2):68-74.

doi: $10.5606 /$ jebms.2020.75615

Received : August 23, 2020

Accepted : September 06, 2020

Published online : November 09, 2020

@2020 Journal of Experimental and Basic Medical Sciences. All rights reserved.

\section{ABSTRACT}

However, unbeknown probiotic consumption began centuries ago when fermented foods such as bread, wine and beer were introduced to the human diet. Recent technological advances in medicine have made it possible to examine the intestinal microflora and its relationship to mental health and autism.

Keywords: Autism, mental health, microbiota, probiotics.

Probiotics are living microorganisms. ${ }^{[10]}$ They are found in fermented products, such as kefir and pickles. ${ }^{[11]}$ Research has shown that probiotics, as part of a healthy diet, are effective as anxiolytic and antidepressive agents. ${ }^{[12]}$

Probiotic consumption increases the levels of neurotransmitter gaminobutyric acid (GABA) and the neuromodulator serotonin in the central nervous system, which are critical in depression. Low proinflammatory cytokine levels, previously found to be inversely associated with mood disorders, were observed in rodents treated with probiotics. ${ }^{[13,14]}$

\section{Major depression}

Many studies have found significant improvement in patients with major depression as a result of taking probiotic supplements, whereas some clinical studies in healthy subjects have found no significant effect of probiotic consumption on stress and anxiety. ${ }^{[15,16]}$

\section{GASTROINTESTINAL MICROFLORA AND AFFECTING FACTORS}

While the gastrointestinal tract is sterile at birth, the normal microflora is formed in early infancy and remains. The sources of the newborn's gut flora are the vaginal and fecal flora of the mother during birth. ${ }^{[17]} 48$ hours after birth, there are enterobacteriaceae, staphylococci and streptococci in the column; on the $2^{\text {nd }}$ and $5^{\text {th }}$ days bifidobacteria 
are found, and after a week, pathogens such as enterococcus and clostridium are reduced. ${ }^{[18]}$ The colonization factors are affected by the food eaten by the mother, the mother's gestational age, mode of delivery - normal birth or C-section - baby's diet (breast milk or formula), and probiotic intake. ${ }^{[17,18]}$ Pathogens such as enterococcus and clostridium are reduced. ${ }^{[18]}$ The colonization factors are affected by the food eaten by the mother, the mother's gestational age, mode of delivery - normal birth or C-section - baby's diet (breast milk or formula), and probiotic intake. ${ }^{[17,18]}$

Between 400 and 1,000 different bacterial species live in the human intestine, and they can weigh up to $1 \mathrm{~kg}^{\left[{ }^{[19]}\right.}$ There are $10^{11}$ cells and 100 trillion bacterial cells per gram of colon content. The number of bacteria in a human body exceeds the number of body cells. ${ }^{[20]}$

Most of the microorganisms are located in the colon. Firmicutes make up 70 percent of the colon microbiota. ${ }^{[21]}$ The functions of the bowel microbiota are: stimulation of innate immunity, the synthesis and metabolism of some nutrients, hormones and vitamins as well as ensuring the removal of the toxins. ${ }^{[22]}$

\section{The Regulatory Mechanism of the Bowel Microbiota on Brain Development and Function}

Recent animal studies have shown that the physiology and the habitat of the microbiota are altered by the secretion of the hormones and neurotransmitters triggered by stress and emotional changes.

Many important molecules that have neuroactive functions are produced by microorganisms. ${ }^{[23]}$ Some strains can produce specific neurotransmitters and neuromodulators. Dopamine, noradrenaline, GABA, serotonin, catecholamines and acetylcholine are produced by bacteria. These bacteria can be found in the intestinal microbiota.

Lactobacillus spp. and Bifidobacterium spp. produce GABA. ${ }^{[2]}$ Escherichia spp., Bacillus spp. and produces acetylcholine. Neurotransmitters secreted from intestinal bacteria are released by the epithelial cells of the lumen. ${ }^{[25]}$

In contrast, molecules in the enteric nervous system can activate neural signaling in the central nervous system and thus control some of the functions of the brain. Various bacterial strains have been shown to mediate behavioral effects via the vagus nerve. ${ }^{[26]}$
Tryptophan is the amino acid precursor of the neurotransmitter serotonin as well as of the active metabolites in the kynurenine pathway. Only 5\% of the systemic tryptophan is metabolized into serotonin. Indoleamine 2,3 dioxygenase - one of the two enzymes that activates this metabolism is found in all tissues and the other - tryptophan 2.3 dioxygenase - is found in the liver. These two enzymes control cytokines and corticosteroid. Their increased activation can lead to serotonin depletion and thus to a depressive mood. ${ }^{[27]}$

Through microbial fermentation of dietary fibre, short-chain fatty acids (SCFA) are produced in the colon. SCFAs are known to have neuroactive properties. For example, it has been found that feeding rodents with overdosed propionate has triggered neuro-inflammatory responses and behaviour related to neurodevelopment disorders. ${ }^{[28]}$

Propionate is used as a food preservative and it is reported that it is associated with increased incidences of autism. SCFA's also regulate the immune system of the bowel which has effects on the central nervous system. ${ }^{[29]}$

\section{PROBIOTICS EFFECTS ON MENTAL HEALTH}

Many studies have shown that probiotics have health benefits. However, other studies on the relationship between probiotics and mental health have shown contrary effects. ${ }^{[30]}$

A double blind, placebo-controlled study, using various probiotic types, (B. longum R0175 and L. helveticus R0052), found beneficial effects on angerhostility, depression, and anxiety. ${ }^{[3]]}$ Consumption of a yogurt that contained L.casei improved the mental health of healthy subjects. ${ }^{[32]}$ The consumption of probiotic supplements, (B. bifidum, L. casei and L. acidophilus), for 4 weeks in 40 adult individuals who had depression led to significant improvements in their mood. ${ }^{[33]} \mathrm{L}$. acidophilus Probiotics Effects on Mental Health. The effects of probiotics on mental health. ${ }^{[34]} \mathrm{L}$. acidophilus), reduced the severity of autism in 33 children. ${ }^{[35]} A$ recent study on probiotic consumption, (B. longum and L. helveticus), has shown significant results in treating mood disorders. ${ }^{[36]}$

\section{WHAT IS AUTISM AND HOW IS IT DIAGNOSED?}

The term autism was first coined by American child psychiatrist Leo Kanner in 1943, to describe a 
syndrome of 11 symptoms, including repetitive motor behaviors, obsession and echolalia. Such behavioral models are used in the diagnosis of autistic children to this day. Research has uncovered connections between diet and autism, centering on fatty acid metabolic pathways. ${ }^{[37]}$

Short-chain fatty acids (SCFAs), namely, acetic acid (AA), propionic acid (PPA), and butyric acid (BA), provide energy to colon cells after the probiotics breaking down the dietary fibre.SCFAs (especially propionates) have broad effects on the physiology of the nervous system and are associated with the pathogenesis of autism spectrum disorder (ASD). In fact, higher levels of AA and PPA found in food preservatives are known to induce autistic-like behaviors in rodents as well as children with an ASD diagnosis. ${ }^{[38,39]}$

Leo Kanner mentions that children with ASD are persistent in maintaining sameness/routine and have trouble forming grammatically correct sentences,(45). Physicians play an important role in early diagnosis by testing various symptoms. ${ }^{[40]}$ The severity of these symptoms varies significantly among children with ASD. The typical age of onset is $>3$ years. As these disorders may be mild diagnosis may be difficult children start school. Physicians and teachers could identify a child with ASD easily by comparing their behaviour with other children. Diagnosing children at both ends of the spectrum can be difficult. It would be difficult to distinguish severely afflicted children with isolated autistic symptoms from the ones with serious mental disorders as well as distinguishing children with mild ASD from those who have language disorders or social anxiety. ${ }^{[1]}$ Physicians play an important role in early diagnosis by testing various symptoms. ${ }^{[40]}$ The severity of these symptoms varies significantly among children with ASD. The typical onset of age is seen after 3 years, and these disorders may be mild and therefore would be difficult to identify before the school age. Medical doctors and teachers could identify a child with ASD easily by comparing their behaviours with other children.Diagnosing children at both ends of the spectrum can be difficult. It would be difficult to distinguish severely afflicted children with isolated autistic symptoms from the ones with serious mental disorders as well as distinguishing a mild ASD from those who have language disorder or social anxiety. ${ }^{[4]}$

In the majority of tests on children with ASD, an ordinary physical examination is applied. The physical examination should include tests for fragile $X$ syndrome or tuberous sclerosis with secondary causes and dysmorphic features. Currently there is no blood tests or radiological tests to diagnose ASD. Diagnostic yield obtained from biomedical research is low. ${ }^{[42]}$ Currently there is no laboratory or radiological tests to diagnose ASD. Diagnostic yield obtained from biomedical research is low. ${ }^{[42]}$

Many parameters on ASD recommend investigation of Fragile $X$ syndrome, regular karyotyping, audiology testing and clinically related DNA analysis for other research. ${ }^{[43]}$

\section{A general diagnostic test is summarised below.}

The presence of at least two from the category (1), and one from (2) and (3) and the total number of (1), (2) and (3) should sum up to six (or more) for a diagnosis. (1), (2) and (3) should sum up to six (or more) for a diagnosis.

1. At least two of the following as manifested by an impairment in social interaction

(a) A marked deterioration in handarm movements, the stance of the body, facial expression, lessened or no eye contact and many other nonverbal behaviours during communication

(b) Inability to develop friendships appropriate to developmental level,

(c) A lack of interest in seeking to share their achievements or interests with other people (e.g. not showing or sharing objects of interest),objects of interest),

(d) Lack of social or emotional reciprocity

2. At least one of the following in communication as manifested by a qualitative impairment:

(a) A delay in the development of spoken language,

(b) Inability or a marked impairment in initiating a conversation with others for the ones that can conduct adequate speech,

(c) Stereotyped or repetitive motor movements, use of object or speech,

(d) Uninterested in imaginative or social imitation-based games appropriate to his/her developmental level, uninterested in imaginative or social imitation based games appropriate to his/her developmental level,

3. At least one of the following as manifested by one's restricted, repetitive and stereotyped patterns in behavioural interests and activities. 
(a) Focus on the unusual stereotyped or restrictive interest patterns,

(b) Inflexible adherence to routines and insistence on sameness

(c) Persistent preoccupation with objects and tinkering.

(d) Delays and abnormal functioning in at least one of the following areas before the age of 3

1. Social interaction,

2. Language used in social communication,

3. Symbolic or imaginative play.

(e) This disorder cannot be explained better with Rett's disorder or childhood disintegrative disorder. ${ }^{[44]}$

\section{THE INTESTINAL MICROBIOTA AND AUTISM}

In recent years, the possible role of the intestinal microbiota in the pathogenesis of autism has been investigated using animal models. Dysbiosis is a symptom of ASD, with possible Bacteroidetes and Firmicutes phyla imbalance accompanied by increased amounts of Lactobacillus, Sutterella, Prevotella, Ruminococcus and Alcaligenaceae families in the gut flora. ${ }^{[45,46]}$ These findings show that more than half of the patients with ASD and gastrointestinal (GI) symptoms have increased Sutterella population. This may play an important role in the pathogenesis of ASD, since Sutturella is absent in people with Gl symptoms without ASD. ${ }^{[4]}$ Studies show that there is an increased population of Sutturella and a decreased population of Prevotella in people with ASD. ${ }^{[47]}$ Prevotella is believed to be of high importance to the bowel microbiota and is involved in maintaining the well-being of the colon. Increased Prevotella population can have beneficial effects in many areas, eg. improved glucose metabolism. Prevotella, ${ }^{[47]}$ Prevotella is believed to be of high importance to the bowel mikrobiota and is responsible of the maintenance of the well-being the colon. Increased prevotella population can have beneficial effects in many areas, eg. improved glucose metabolism.

Another gram-positive, anaerobic bacterial genus, clostridium, has been found to be present at more than 10 times the level found in the feces of control subjects in children with ASD. Moreover, overall reduced amounts of anaerobic bacteria were found in children with ASD. ${ }^{[48]}$ Clostridium is one of the largest genera with 180 species. ${ }^{[49-51]}$ Although Clostridium perfringens has been found in the soil and in the $\mathrm{Gl}$ tracts of animals and humans, it is known that it can cause various diseases by producing potent toxins. ${ }^{[1]}$ Clostridium histolyticum is not only higher in patients with ASD, but also in their healthy siblings when compared with controls. ${ }^{[52]}$

Four studies on ASD have recorded lower levels of Prevotella. Three of these studies have found a significant effect. ${ }^{[47]}$ Liu et al., ${ }^{[53]}$ found higher levels of Prevotella melaninogenica. Oral intake of probiotics in patients with ASD have not been found to have positive impact. ${ }^{[54]}$

The rate of Bacteriodetes/Firmicutes and the amount of Clostridiales are found to be greater in patients with ASD and GI problems. ${ }^{[55]}$

Emerging evidence suggests that the intestinal microbiota plays an important role in ASD, however the communication between the gut and the brain is limited. It has been suggested that the neuroimmune system contributes to ASD symptomatology through the gutbrain axis. ${ }^{[56]}$

Intestinal microbiota can affect cognitive development and cognitive function directly by modulating the permeability of the bloodbrain barrier and changing neurochemical concentrations. ${ }^{[57]}$ Neural signals from the gut can reach the brain through the vagus nerve, dorsal root ganglion afferents or via somatosensory afferents. ${ }^{[58]}$

Clinical studies of individuals with ASD have revealed that disorders of the brain are usually accompanied by infections or composition alterations in the gut microbiota, caused by exposure or chronic antibiotic use. ${ }^{[53,59]}$

Some bacterial species, i.e. Bifidobacterium (bifidum, breve), and Lactobacillus (acidophilus, casei) are commonly used as probiotics, ${ }^{[34]}$ are commonly used as probiotics. ${ }^{[34]}$

Despite the high amounts of Clostridia, Desulfovibrio and Sutterella in the feces of patients with ASD, lower amounts of Prevotella and bifidobacterium have been found. A limited number of clinical trials were conducted on children with ASD concerning the therapeutic effects of probiotics. Adams et al., ${ }^{[59]}$ found that most probiotics, with the exception of high levels of lactobacillus, have no significant beneficial effect, ${ }^{[59]}$ revealed that most probiotics, except for high amounts of lactobacillus, have no significant beneficial effect. 
The number of Clostridium species (especially C. histolyticum group) found in the stool was greater in children with ASD than in controls. Severely afflicted children with autism had higher levels of Bacteriodetes with lower levels of bifidobacterum. ${ }^{[59]}$

\section{Conclusion}

Research on the effects of gut microbiota on mental health and autism is in its debut. However, the research that has been done up until now claims that mood disorders that can play a role in the pathogenesis of autism are closely related to the alterations of the gut microbiota. In order to regulate the microbiota, probiotics can be of help. Nevertheless, studies looking at the relationship between autism and microbiota have yet to provide unequivocal support for this thesis. Numerous confounding factors, such as the diversity of the microorganisms consumed and the dosage and duration of application, could play a part in this and these variables should should be carefully controlled in the design of future studies. Although therapeutic applications of this research are still unclear, current data suggests that the presence of different types of bacteria in fecal specimens can serve as a diagnostic tool in more than half of ASD cases.

\section{Declaration of conflicting interests}

The authors declared no conflicts of interest with respect to the authorship and/or publication of this article.

\section{Funding}

The authors received no financial support for the research and/or authorship of this article.

\section{REFERENCES}

1. World Health Organization. Depression and other common mental disorders: Global health estimates. Geneva: World Health Organization; 2017.

2. World Health Organization. Mental health action plan 20132020. Geneva: World Health Organization; 2013.

3. Lozupone CA, Stombaugh Jl, Gordon Jl, Jansson JK, Knight R. Diversity, stability and resilience of the human gut microbiota. Nature 2012;489:220-30.

4. Rogers $G B$, Keating $D J$, Young RL, Wong $M L$, Licinio $J$, Wesselingh $\mathrm{S}$. From gut dysbiosis to altered brain function and mental illness: mechanisms and pathways. Mol Psychiatry 2016;21:738-48.

5. Sánchez-Villegas $A$, Delgado-Rodríguez $M$, Alonso $A$, Schlatter J, Lahortiga F, Serra Majem L, et al. Association of the Mediterranean dietary pattern with the incidence of depression: the Seguimiento Universidad de Navarra/ University of Navarra follow-up (SUN) cohort. Arch Gen Psychiatry 2009;66:1090-8.
6. Choi JY, Park MN, Kim CS, Lee YK, Choi EY, Chun WY, et al. Long-term consumption of sugar-sweetened beverage during the growth period promotes social aggression in adult mice with proinflammatory responses in the brain. Sci Rep 2017;7:45693.

7. Markus CR. Dietary amino acids and brain serotonin function; implications for stress-related affective changes. Neuromolecular Med 2008;10:247-58.

8. Shabbir F, Patel A, Mattison C, Bose S, Krishnamohan $R$, Sweeney $E$, et al. Effect of diet on serotonergic neurotransmission in depression. Neurochem Int 2013;62:324-9.

9. Opie RS, Itsiopoulos C, Parletta N, SanchezVillegas A, Akbaraly TN, Ruusunen A, et al. Dietary recommendations for the prevention of depression. Nutr Neurosci 2017;20:161-71.

10. O'Toole PW, Marchesi JR, Hill C. Next-generation probiotics: the spectrum from probiotics to live biotherapeutics. Nat Microbiol 2017;2:17057.

11. Parvez S, Malik KA, Ah Kang S, Kim HY. Probiotics and their fermented food products are beneficial for health. J Appl Microbiol 2006;100:1171-85.

12. Sarkar A, Lehto SM, Harty S, Dinan TG, Cryan JF, Burnet PWJ. Psychobiotics and the Manipulation of BacteriaGut-Brain Signals. Trends Neurosci 2016;39:763-81.

13. Desbonnet L, Garrett L, Clarke G, Kiely B, Cryan JF, Dinan TG. Effects of the probiotic Bifidobacterium infantis in the maternal separation model of depression. Neuroscience 2010;170:1179-88.

14. Ait-Belgnaoui A, Durand H, Cartier C, Chaumaz G, Eutamene $H$, Ferrier $L$ et al. Prevention of gut leakiness by a probiotic treatment leads to attenuated HPA response to an acute psychological stress in rats. Psychoneuroendocrinology 2012;37:1885-95.

15. Akkasheh G, Kashani-Poor Z, Tajabadi-Ebrahimi M, Jafari $P$, Akbari $H$, Taghizadeh $M$, et al. Clinical and metabolic response to probiotic administration in patients with major depressive disorder: A randomized, double-blind, placebo-controlled trial. Nutrition 2016;32:315-20.

16. Kazemi A,Noorbala AA,AzamK,DjafarianK,JJoFF.Effect of prebiotic and probioticsupple-mentation on circulating pro-inflammatory cytokines and urinarycortisol levels in patients with major depressive disorder: a double-blind, placebo-controlled randomized clinical trial. Clin Nutr 2019;52:596-602.

17. Putignani L, Del Chierico F, Petrucca A, Vernocchi $P$, Dallapiccola B. The human gut microbiota: a dynamic interplay with the host from birth to senescence settled during childhood. Pediatr Res 2014;76:2-10.

18. Coşkun T. Pro- Pre- ve Sinbiyotikler, Çocuk Sağlığı ve Hastalıkları Dergisi 2006;49:128-48.

19. Mazmanian SK, Round JL, Kasper DL. A microbial symbiosis factor prevents intestinal inflammatory disease. Nature 2008;453:620-5.

20. Ley RE, Peterson DA, Gordon Jl. Ecological and evolutionary forces shaping microbial diversity in the human intestine. Cell 2006;124:837-48. 
21. Sartor RB. Microbial influences in inflammatory bowel diseases. Gastroenterology 2008;134:577-94.

22. Garrett WS. Cancer and the microbiota. Science 2015;348:80-6.

23. Cryan JF, Dinan TG. Mind-altering microorganisms: the impact of the gut microbiota on brain and behaviour. Nat Rev Neurosci 2012;13:701-12.

24. Barrett E, Ross RP, O'Toole PW, Fitzgerald GF, Stanton C. $Y$-Aminobutyric acid production by culturable bacteria from the human intestine. J Appl Microbiol 2012;113:411-7.

25. Dinan TG, Stanton C, Cryan JF. Psychobiotics: a novel class of psychotropic. Biol Psychiatry 2013;74:720-6.

26. Bercik P, Park AJ, Sinclair D, Khoshdel A, Lu J, Huang X, et al. The anxiolytic effect of Bifidobacterium longum NCC3001 involves vagal pathways for gut-brain communication. Neurogastroenterol Motil 2011;23:1132-9.

27. Bercik P, Park AJ, Sinclair D, Khoshdel A, Lu J, Huang X, et al. The anxiolytic effect of Bifidobacterium longum NCC3001 involves vagal pathways for gut-brain communication. Neurogastroenterol Motil 2011;23:1132-9.

28. Foley KA, MacFabe DF, Vaz A, Ossenkopp KP, Kavaliers $M$. Sexually dimorphic effects of prenatal exposure to propionic acid and lipopolysaccharide on social behavior in neonatal, adolescent, and adult rats: implications for autism spectrum disorders. Int J Dev Neurosci 2014;39:68-78.

29. Erny $D$, Hrabě de Angelis $A L$, Jaitin $D$, Wieghofer $P$, Staszewski O, David E, et al. Host microbiota constantly control maturation and function of microglia in the CNS. Nat Neurosci 2015;18:965-77.

30. Sivamaruthi BS, Prasanth MI, Kesika P, Chaiyasut C. Probiotics in human mental health and diseases-A minireview. Trop J Pharm Res 2019;18:889-95.

31. Messaoudi M, Violle N, Bisson JF, Desor D, Javelot $H$, Rougeot $C$. Beneficial psychological effects of a probiotic formulation (Lactobacillus helveticus R0052 and Bifidobacterium longum R0175) in healthy human volunteers. Gut Microbes 2011;2:256-61.

32. Benton D, Williams C, Brown A. Impact of consuming a milk drink containing a probiotic on mood and cognition. Eur J Clin Nutr 2007;61:355-61.

33. Akkasheh $\mathrm{G}$, Kashani-Poor Z, Tajabadi-Ebrahimi M, Jafari $\mathrm{P}$, Akbari H, Taghizadeh M, et al. Clinical and metabolic response to probiotic administration in patients with major depressive disorder: A randomized, double-blind, placebo-controlled trial. Nutrition 2016;32:315-20.

34. Umbrello G, Esposito S. Microbiota and neurologic diseases: potential effects of probiotics. J Transl Med 2016;14:298.

35. West R, Roberts E, Sichel LS, Sichel J. Improvements in gastrointestinal symptoms among children with autism spectrum disorder receiving the delpro ${ }^{\circledast}$ probiotic and immunomodula-tor formulation. J Prob Health 2013;1:102.

36. Romijn AR, Rucklidge JJ, Kuijer RG, Frampton C. A double-blind, randomized, placebo-controlled trial of Lactobacillus helveticus and Bifidobacterium longum for the symptoms of depression. Aust N Z J Psychiatry 2017;51:810-21.
37. Byrne CS, Chambers ES, Morrison DJ, Frost G. The role of short chain fatty acids in appetite regulation and energy homeostasis. Int J Obes (Lond) 2015;39:1331-8.

38. Thomas RH, Meeking MM, Mepham JR, Ticheno $L$, Possmayer F, Liu S, MacFabe DF. The enteric bacterial metabolite propionic acid alters brain and plasma phospholipid molecular species: Further development of a rodent model of autism spectrum disorders. J Neuroinflammation 2012;9:153.

39. MacFabe DF. Enteric short-chain fatty acids: microbial messengers of metabolism, mitochondria, and mind: implications in autism spectrum disorders. Microb Ecol Health Dis 2015;26:28177.

40. Johnson CP, Myers SM; American Academy of Pediatrics Council on Children With Disabilities. Identification and evaluation of children with autism spectrum disorders. Pediatrics 2007;120:1183-215.

41. Baron-Cohen S, Wheelwright S, Cox A, Baird G, Charman T, Swettenham J, et al. Early identification of autism by the CHecklist for Autism in Toddlers (CHAT). J R Soc Med 2000;93:521-5.

42. Barton M, Volkmar F. How commonly are known medical conditions associated with autism? J Autism Dev Disord 1998;28:273-8.

43. Chakrabarti S, Fombonne E. Pervasive developmental disorders in preschool children. JAMA 2001;285:3093-9.

44. Köroğlu E. Psikiyatri Temel Kitabı. Ankara, Hekimler Birliği Yayınevi; 2007.

45. Finegold SM, Dowd SE, Gontcharova V, Liu C, Henley $\mathrm{KE}$, Wolcott RD, et al. Pyrosequencing study of fecal microflora of autistic and control children. Anaerobe 2010;16:444-53.

46. Williams BL, Hornig M, Parekh T, Lipkin WI. Application of novel PCR-based methods for detection, quantitation, and phylogenetic characterization of Sutterella species in intestinal biopsy samples from children with autism and gastrointestinal disturbances. mBio 2012;3:e00261-11.

47. Kang DW, Park JG, Ilhan ZE, Wallstrom G, Labaer J, Adams $J B$, et al. Reduced incidence of Prevotella and other fermenters in intestinal microflora of autistic children. PLoS One 2013;8:e68322.

48. Finegold SM, Dowd SE, Gontcharova V, Liu C, Henley KE, Wolcott RD, et al. Pyrosequencing study of fecal microflora of autistic and control children. Anaerobe 2010;16:444-53.

49. Dürre P. Physiology and Sporulation in Clostridium. Microbiol Spectr 2014;2:TBS-0010-2012.

50. Kovatcheva-Datchary P, Nilsson A, Akrami R, Lee YS, De Vadder F, Arora $T$, et al. Dietary fiber-induced Improvement in glucose metabolism is associated with increased abundance of prevotella. Cell Metab 2015;22:971-82.

51. Ding HT, Taur Y, Walkup JT. Gut Microbiota and Autism: Key Concepts and Findings. J Autism Dev Disord 2017;47:480-9.

52. Strati F, Cavalieri D, Albanese D, De Felice C, Donati C, Hayek J, et al. New evidences on the altered gut microbiota in autism spectrum disorders. Microbiome 2017;5:24. 
53. Liu S, Li E, Sun Z, Fu D, Duan G, Jiang M, et al. Altered gut microbiota and short chain fatty acids in Chinese children with autism spectrum disorder. Sci Rep 2019;9:287.

54. Salvatore S, Pensabene L, Borrelli O, Saps M, Thapar N, Concolino $\mathrm{D}$, et al. Mind the gut: probiotics in paediatric neurogastroenterology. Benef Microbes 2018;9:883-98.

55. Luna RA, Oezguen N, Balderas M, Venkatachalam A, Runge JK, Versalovic J, et al. Distinct MicrobiomeNeuroimmune Signatures Correlate With Functional Abdominal Pain in Children With Autism Spectrum Disorder. Cell Mol Gastroenterol Hepatol 2016;3:218-30.

56. de Theije CG, Wu J, da Silva SL, Kamphuis PJ, Garssen J, Korte SM et al. Pathways underlying the gut-tobrain connection in autism spectrum disorders as future targets for disease management. Eur J Pharmacol
2011;668 Suppl 1:S70-80.

57. Braniste $\mathrm{V}, \mathrm{Al}$-Asmakh $\mathrm{M}$, Kowal C, Anuar F, Abbaspour $A$, Tóth $M$, et al. The gut microbiota influences bloodbrain barrier permeability in mice. Sci Transl Med 2014;6:263ra158.

58. Bravo JA, Forsythe $P$, Chew MV, Escaravage E, Savignac $H M$, Dinan TG, et al. Ingestion of Lactobacillus strain regulates emotional behavior and central GABA receptor expression in a mouse via the vagus nerve. Proc Natl Acad Sci U S A 2011;108:16050-5.

59. Adams JB, Johansen LJ, Powell LD, Quig D, Rubin RA. Gastrointestinal flora and gastrointestinal status in children with autism--comparisons to typical children and correlation with autism severity. BMC Gastroenterol 2011;11:22. 